\title{
Editorial
}

\section{Prevention of Deafness in Bangladesh}

Over $5 \%$ of the world's population or 466 million people has disabling hearing loss (432 million adults and 34 million children) ${ }^{1}$. It is estimated that $50 \%$ of all deafness and hearing impairment is preventable. Although it is not a death causing disease, the implication of hearing impairment for the individual, family and community is tremendous. The far reaching consequences of hearing loss, both in respect of development of communication skills, as well asin social, economic and quality of life terms, warrantan urgent need to highlight the magnitude and severity of the problem.

Deafness is a major public health problem in our country ${ }^{2}$. The prevalence of disabling hearing loss in Bangladesh is $9.6 \%{ }^{3}$. One third of Bangladeshi population suffer from some sort of hearing impairment. These findings came out from the 'National survey on prevalence of hearing impairment in Bangladesh' carried out in 2013 using standard WHO methods. Chronic suppurative otitis media (6.2\%), Otitis media with effusion (5.3\%) and Impacted wax $(11.5 \%)$ were seen as common ear diseases. Actual incidence of noise induced hearing loss, age related hearing loss and ototoxicity in the community were not available but further survey can address it. The prevalence of profound deafness in the survey was seen as $1.2 \%$. From this data it can be estimated that twenty lac children and adults will possibly need cochlear implant in Bangladesh.

Deafness cannot be seen externally; so people recognize it only when the disability is severe. At the same time, even with the deafness revealed clearly, the deaf individual and his family try to hide the handicap. For the same reason, many times a person with hearing loss refuses to use a hearing aid. Deafness in Bangladesh is neglected due to ignorance, lack of awareness, social customs, taboo and misbeliefs. The out-ofpocket expenditure for hearing aid and ear care serveries for rural populationis also apparently high.

A 'National strategy on prevention of deafness and hearing impairment in Bangladesh: 2011-16' was launched with a target of reducing the burden of avoidable deafness and hearing impairment by $90 \%$ from existing level by $2030^{4}$. The country now needs to develop new strategy plans to prevent deafness in Bangladesh. Presence of general awareness, suitable ear and hearing care programs, services, resources, planning, and sensitization of policy makers can strengthen a deafness prevention policy.

Primary prevention can be undertaken to prevent an impairment from occurring (like hearing conservation, rational use of ototoxic drugs, immunization, treating AOM). Secondary prevention is necessary to prevent disability when impairment is already present (like treating COM, screening, ear surgery to reverse $\mathrm{HL}$ ). Whereas a tertiary prevention will be required to prevent/ minimize effects of disability, i.e. prevent handicap (hearing aid, special education, social integration $)^{5}$.

The strategies for prevention of deafness and hearing impairment of World Health Organization categorized primary prevention 
as prevention of causes of deafness and hearing impairment ${ }^{6}$. Major causes include: congenital or early onset childhood hearing loss, chronic otitis media, noise induced hearing loss, inner ear damage by ototoxic drugs. Secondary and tertiary prevention mean eliminating or reducing the effects of deafness and hearing impairment. Early identification followed by prompt and appropriate management can effectively reduce the impact of deafness and hearing loss on the life of an individual. Neonatal and infant hearing screening programs are an effective strategy for early intervention in cases of congenital and early onset hearing loss. Both institutional and community based screening are now needed in Bangladesh.

Deafness prevention program should give priorities to middle ear infection, congenital hearing loss, noise induced hearing loss and inner ear damage by ototoxic drugs. 'Healthy ear district' and 'Less noisy city' concepts can be adapted at secondary levels. Deafness prevention program should be integrated with primary health care.

\footnotetext{
Md Abul Hasnat Joarder ${ }^{1}$, Md Nazmul Islam²

${ }^{1}$ Chief of Otology Division, Dept. of Otolaryngology-Head \& Neck Surgery, Bangabandhu Sheikh Mujib Medical University, Dhaka. ${ }^{2}$ Line Director, Medical Education and Health Manpower Development, Directorate General of Medical Education, Dhaka.
}

\section{References:}

1. World Health Organization. Deafness and Hearing Loss, 2020Available at : https://www.who.int/news-room/factsheets/detail/deafness-and-hearingloss [Accessed on 26 October 2020]

2. Alauddin $M$ and Joarder $A H$. Deafness in Bangladesh. In : Eds Suzuki J, Kobayashi and Koga K. Hearing Impairment- An Invisible Disability. Springer-Verlag Tokyo 2004.

3. World Health Organization, SEAR, Country Office in Bangladesh, Dhaka and Bangabandhu Sheikh Mujib Medical University, 2013.National Survey on prevalence of hearing impairment in Bangladesh.

4. Non Communicable Disease Unit, Director General of Health Services. National Strategy on prevention of deafness and hearing impairment in Bangladesh: 2011-16. Dhaka: DGHS, Ministry of Health and Family Welfare; November, 2011.

5. Noh $\mathrm{K}$ and Chang SO. Prevention of hearing impairment and deafnessspecial problem in Korea. In : Eds Suzuki J, Kobayashi and Koga K. Hearing Impairment - An Invisible Disability. Springer-Verlag Tokyo 2004.

6. World Health Organization. Strategies for prevention of Deafness and Hearing impairment, Available at https:// www.who.int/pbd/deafness/activities/ strategies/en/ [Accessed on 27 October 2020] 